\title{
Mesoporous Silica Nanoparticles as a Nanocarrier for Delivery of Vitamin C
}

\author{
Ladan Rashidi ${ }^{1}$, Ebrahim Vasheghani-Farahani ${ }^{1, *}$, Khosrow Rostami ${ }^{2}$, Fariba Gangi ${ }^{1}$, \\ Masoud Fallahpour ${ }^{2}$ \\ ${ }^{1}$ Biotechnology Division, Department of Chemical Engineering, Tarbiat Modares University, Tehran, IR Iran \\ 2 Biotechnology Center, Iranian Research Organization for Science \& Technology (IROST), Tehran, IR Iran \\ *Corresponding author: Ebrahim Vasheghani-Farahani, Biotechnology Division, Department of Chemical Engineering, Tarbiat Modares University, Tehran, IR Iran. Tel.: + 98- \\ 2182883338; Fax: + 98-2182884931, E-mail: evf@modares.ac.ir
}

Received: August 18, 2013; Revised: September 10, 2013; Accepted: September 20, 2013

Background: In the last decades, mesoporous silica nanoparticles (MSNs) are improved for drug delivery, imaging, and biomedical applications due to their special properties such as large surface area, high drug loading capacity, tunable pore size, and modification of surface area by functional groups.

Objectives: The aim of this study was to evaluate MSNs as carriers for oral colon-specific and human plasma blood delivery of vitamin C.

Materials and Methods: In this work, mesoporous silica nanoparticles were synthesized and characterized by transmission electron microscopy (TEM), scanning electron microscopy (SEM), X-ray diffraction (XRD), and N2- adsorption. Then MSNs were loaded by L-ascorbic acid ( $\mathrm{AscH} 2$ ), and the release of L-ascorbic acid from AscH 2-MSNs into the simulated fluids in different pHs was investigated, including simulated gastric fluid (SGF, pH, 1.2), simulated intestinal fluid (SIF, pH, 6.8), and simulated body fluid (SBF, pH, 7.4). The amount of loaded AscH 2 into the MSNs was determined by thermal gravimetric analysis (TGA).

Results: Synthesized MSNs were spheres and the average diameter of them was $100 \pm 9 \mathrm{~nm}$. Results showed that about 567.8 nanomole of vitamin C. It was found that the burst release of AscH 2 into SGF was slower than SIF and SBF.

Conclusions: The rate of AscH 2 release from the nanoparticles into alkaline solutions was faster than acidic solutions because of electrostatic interactions between vitamin C and MSNs surface. The loading amount of Vitamin C was dependent on the surface of chemical moiety of MSNs and the steric effects of vitamin C structure.

Keywords: Ascorbic Acid; Mesoporous Silica; Nanoparticles; Release; Vitamin C

\section{Background}

L-ascorbic acid is a water - soluble vitamin and it is clear that human body cannot store it. Vitamin C is needed for healing wounds and repairing and maintaining bones and teeth. In addition, vitamin $\mathrm{C}$ helps the body make collagen, an important protein used to make skin, cartilage, tendons, ligaments, and blood vessels. It is present in fruits like orange, lemons, grapefruit, watermelon, papaya, strawberries, cantaloupe, mango, pineapple, raspberries, cherries, and it is also found in green leafy vegetables, tomatoes, broccoli, green and red peppers, cauliflower, and cabbage (1). It is noted that recommended dietary al-

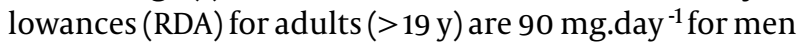
and $75 \mathrm{mg}^{-d a y}{ }^{-1}$ for women (2). L-ascorbic acid $\left(\mathrm{C}_{6} \mathrm{H}_{8} \mathrm{O}_{6}\right)$ is the trivial name of vitamin $\mathrm{C}$. The chemical name is 2-oxo-L-threo-hexono-1, 4-lactone-2, 3-enediol. L-ascorbic and dehydroascorbic acid are the major dietary forms of vitamin C (Figure 1), which is known as the biological function for vitamin $\mathrm{C}$ (ascorbic acid, AscH 2 ; ascorbate, AscH) ( 3 ).

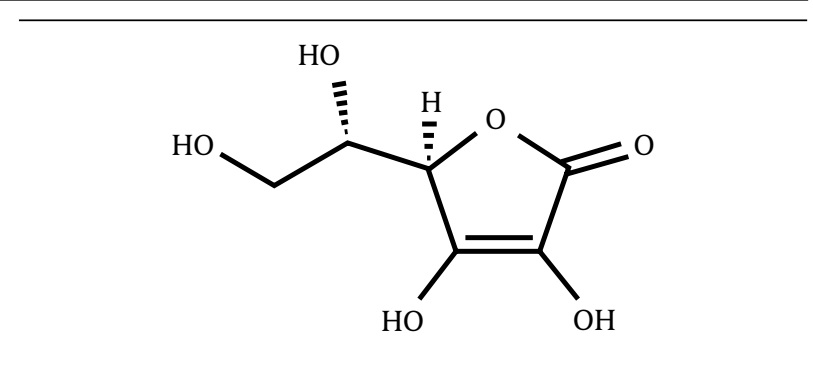

Figure 1. Chemical Structure of L-Ascorbic Acid

Ascorbic acid enhances the availability and absorption of iron from non-heme iron sources (4). Ascorbate serves as a reducing cofactor for many enzymes and has pro-oxidant effects (5). Ascorbate can readily oxidize to produce $\mathrm{H}_{2} \mathrm{O}_{2}$. Therefore, pharmacological ascorbate has been proposed as a pro-drug for the delivery of $\mathrm{H}_{2} \mathrm{O}_{2}$ to tumors $(6,7)$. It is an antioxidant molecule that quenches reactive oxygen species (ROS), inhibiting ROS-mediated nitric 
oxide (NO) inactivation $(8,9)$. It was reported that ocular tissue accumulates higher concentration of ascorbic acid than other tissues, because ocular ascorbic acid, being an antioxidant, defends the cornea and lens against photooxidative damage (10). MSNs have been developed for its potential biological applications in the last decade (11, 12). MSNs were designed for imaging (13) or MRI (14) and drug delivery, such as Paclitaxel (15), Methotrexate (16), Telmisartan (17), Cysteine (18), and Chlorambucil (19). It was reported that mesoporous silica was used as a carrier for vitamins. Mesoporous silica containing gate-like scaffoldings were used for the controlled delivery of vitamin B2 (20) and as a carrier for VB1 release in oral applications (21). Vitamin C dissolves well in water to give mildly acidic solution, as a result it cannot be stored in the body.

\section{Objectives}

In this research, the potential of MSNs as nanocarriers for delivery of vitamin $\mathrm{C}$ was evaluated. These nanoparticles were synthesized, characterized, and evaluated as carriers for oral colon-specific or human plasma blood delivery of vitamin C (ascorbic acid). MSNs were loaded with ascorbic acid and the release of ascorbic acid from these nanocarriers into SGF, SIF, and SBF was studied.

\section{Materials and Methods}

\subsection{Materials}

N-cetyltrimethylammonium bromide (CTAB), tetraethylorthosilicate(TEOS), sodium hydroxide $(\mathrm{NaOH})$, and hydrochloric acid ( $\mathrm{HCl}, 37 \%$ ) were obtained from Merck Company (Germany). L-ascorbic acid was prepared from Sigma-Aldrich Company (USA). Imidazole buffer at $\mathrm{pH} 7.4$ was prepared by $0.2 \mathrm{M}$ stock standard solution of imidazole. In addition; SGF was prepared by $0.1 \mathrm{M} \mathrm{HCl}$ at $\mathrm{pH} 1.2$. All solutions were prepared with deionized water. Simulated body fluid was prepared as described by Xu et al. (22) as the following: $\mathrm{NaCl}$ (7.996 g), $\mathrm{NaHCO}_{3}(0.350 \mathrm{~g}), \mathrm{KCl}(0.224 \mathrm{~g}), \mathrm{K}_{2} \mathrm{HPO}_{4} .3 \mathrm{H}_{2} \mathrm{O}$ (0.228 g), $\mathrm{MgCl}_{2} 6 \mathrm{H}_{2} \mathrm{O}(0.305 \mathrm{~g}), 1 \mathrm{~N} \mathrm{HCl}(40 \mathrm{~mL}), \mathrm{CaCl}_{2}(0.278$ g), $\mathrm{Na}_{2} \mathrm{SO}_{4}(0.071 \mathrm{~g}), \mathrm{NH}_{2} \mathrm{C}\left(\mathrm{CH}_{2} \mathrm{OH}\right) 3(6.057 \mathrm{~g})$ in 1.0 liter deionized water. All the aforementioned chemical reagents were prepared from Merck Company (Germany).

\subsection{Preparation of Samples}

\subsubsection{Synthesis of Mesoporous Silica Nanoparticles} (MSNs)

MSNs were synthesized as follows: $1 \mathrm{~g}$ of CTAB was dissolved in $480 \mathrm{~mL}$ of nano pure water. Then $3.5 \mathrm{~mL}$ of 2.0 $\mathrm{M} \mathrm{NaOH}(\mathrm{aq})$ was added to the CTAB solution at $80{ }^{\circ} \mathrm{C}$. At $80^{\circ} \mathrm{C}, 5 \mathrm{~mL}$ of TEOS was added drop wise at a rate of $1 \mathrm{~mL}^{\mathrm{min}} \mathrm{m}^{-1}$ to the CTAB solution. The CTAB mixture was stirred vigorously at $80{ }^{\circ} \mathrm{C}$ for 2 hours. White precipitate was produced and isolated by filtration $(0.45 \mu \mathrm{m}$ poly- propylene filter), then washed with abundant water and methanol, and then dried under vacuum oven. The surfactant was removed via calcination at $540^{\circ} \mathrm{C}$ for 4 hours at a heating rate of $1^{\circ} \mathrm{C} \cdot \mathrm{min}^{-1}$.

\subsubsection{Ascorbic Acid Loading}

There was $300 \mathrm{mg}$ of calcined MSNs added into $10 \mathrm{~mL}$ nanopure water containing $30 \mathrm{mg} \cdot \mathrm{mL}^{-1}$ ascorbic acid in darkness, while stirring at $200 \mathrm{rpm}$ and room temperature $\left(25^{\circ} \mathrm{C}\right)$ for 24 hours. Then, MSNs loaded with ascorbic acid (AscH 2-MSNs) were removed from water solution by filtration, and washed by deionized water three times, and dried under vacuum at room temperature. TGA analysis was used to measure the amount of ascorbic acid which was loaded into the MSNs.

\subsection{Mesoporous Silica Nanoparticles Character- ization}

Synthesized MSNs were characterized by XRD, TEM, SEM, and $\mathrm{N}_{2}$-adsorption. Small angle XRD patterns were recorded on a Philips X'Pert multipurpose diffractometer which is equipped with $\mathrm{CuK} \alpha$ radiation $\left(\lambda=1.5406 \mathrm{~A}^{\circ}\right)$ operating at $40 \mathrm{kV}$ and $20 \mathrm{~mA}$. The diffractograms were recorded over the range $1-10.0^{\circ}(2 \theta)$ with a step size of $0.02^{\circ}$. Surface area and porosity were determined from nitrogen adsorption - desorption isotherms obtained at $-196^{\circ} \mathrm{C}$ on a Micromeritics ASAP 2010 analyzer. Pore size distributions were calculated from the desorption branch using the Barrett-JoynerHalenda (BJH) method and pore volumes measured at P/P0 $=0.2-0.4$. Particle morphology was analyzed by scanning electron microscopy (SEM, Philips XL - 30). In addition, the structural properties and morphology of the MSN were studied by transmission electron microscopy (TEM, Philips CM120).

\subsection{Release Studies in Simulated Fluids}

Three different media including SGF ( $\mathrm{HCl}$ aqueous solution, $\mathrm{pH}$ 1.2), SIF (7.4), and SBF (7.4) were prepared. The release of AscH 2 was determined by soaking $10 \mathrm{mg}$ of $\mathrm{AscH}$ 2-MSNs into a vial containing one of the aforementioned simulated solutions ( $2 \mathrm{~mL}$ ). A blank was prepared for each of simulated solutions. Vials were put on the shaking water bath at $37^{\circ} \mathrm{C}$ and $80 \mathrm{rpm}$. Then the dissolution medium was sampled at a predetermined time interval, and replaced by fresh medium immediately. The withdrawn samples containing released AscH 2 were analyzed by Cary $100 \mathrm{UV}$ - Vis spectrometer at $245 \mathrm{~nm}$ for SGF and $265 \mathrm{~nm}$ for SIF and SBF. The measurements were carried out in triplicate and the average standard deviation of them was less than $4 \%$.

\section{Results}

\subsection{Characteristics of Synthesized Mesoporous Sil-} ica Nanoparticles 
MSNs were characterized after they were synthesized by several techniques. Figure 2 provides TEM image of the MSNs. It can be seen that all the nanoparticles were spheres and the average diameter of them was measured of $100 \pm 9 \mathrm{~nm}$.

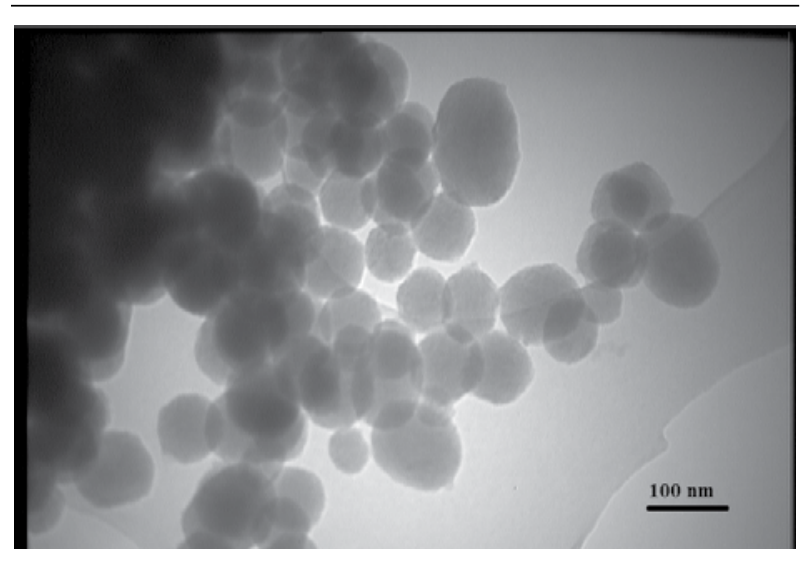

Figure 2. TEM Image of the MSNs.

The SEM image of synthesized MSNs is shown in Figure 3. It was indicated that these particles were spherical with almost uniform size.

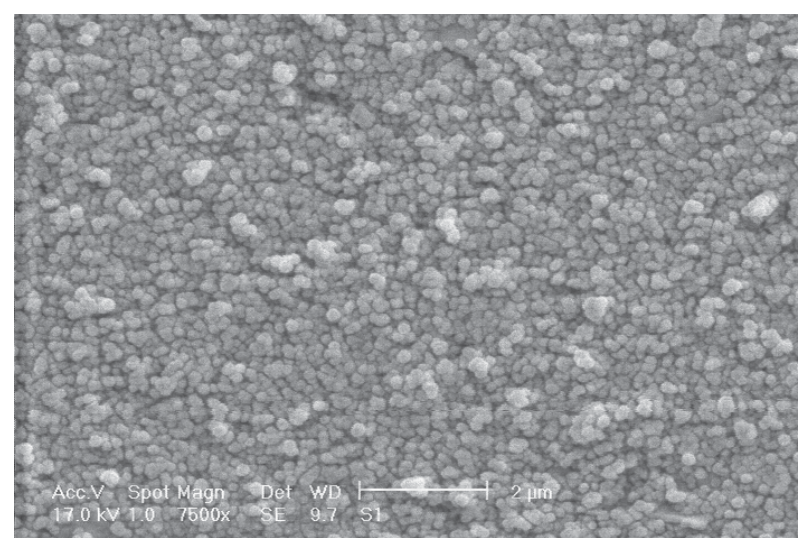

Figure 3. SEM Image of Synthesized MSNs

XRD patterns of MSNs and MSNs loaded by ascorbic acid (AscH 2 -MSNs) are presented in Figure 4 where the ordered mesoporous structure of the synthesized nano particles is addressed. The XRD patterns with four peaks are associated with (100), (110), (200) and (210) diffraction planes, respectively, in the MCM-41 type MSNs, indicates that this material exhibits a well ordered arrangement ( 22 ). The $\mathrm{a}^{\circ}$ lattice parameter, the repeat distance between two pore centers, calculated by $\mathrm{a}^{\circ}=(2 / \sqrt{3}) \mathrm{d} 100$ relation for MSNs, AscH 2 -MSNs are $4.72 \mathrm{~nm}, 4.45 \mathrm{~nm}$, respectively.

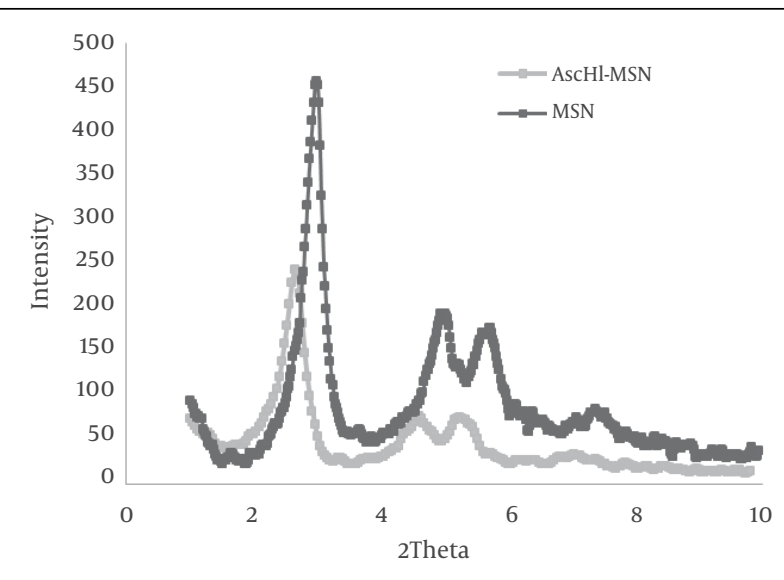

Figure 4. XRD Patterns of MSN and AscH 2-MSNs.

The $\mathrm{N}_{2}$ adsorption-desorption isotherms of ascorbic acid loaded and unloaded MSNs are shown in Figure $5 \mathrm{~A}$. The BJH method was used to calculate the pore size distributions of mesoporous silica spheres. Pore size distributions of MSNs with and without ascorbic acid are presented in Figure $5 \mathrm{~B}$. The pore volume of MSNs was decreased from 0.7909 to $0.6969 \mathrm{~cm}^{3} . \mathrm{g}^{-1}$ due to loading of ascorbic acid. The pore diameter of MSNs and AscH 2 -MSNs were 2.44 and 2.4, respectively. The BET surface areas of MSNs and AscH 2 -MSNs pores were 1084 and $857.07 \mathrm{~m}^{2} . \mathrm{g}^{-1}$, respectively.
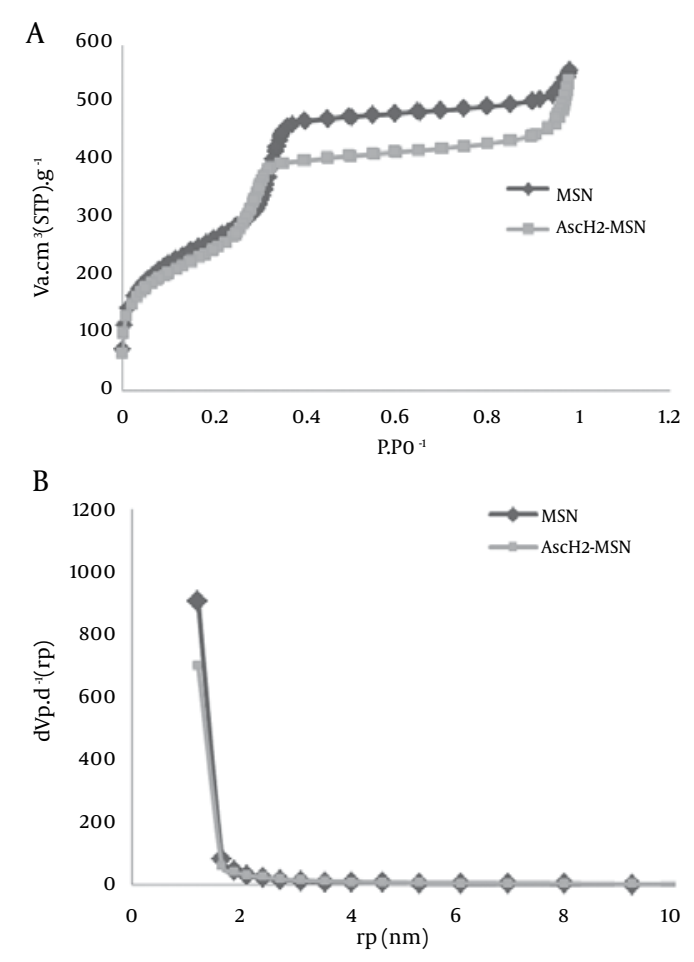

Figure 5. A) Nitrogen adsorption-desorption isotherms of MSNs and AscH 2- MSNs. B) Corresponding pore-size distribution curves of MSNs and AscH 2-MSNs. 
The corresponding results showed that about 567.8 nmole of AscH 2/g of MSNs were loaded. The in vitro release of AscH 2 has been performed in three simulated fluids: gastric fluid ( $\mathrm{pH} 1.2)$, small intestinal fluid $(\mathrm{pH}$ 7.4), and simulated body fluid ( $\mathrm{pH}$ 7.4). During the first 30 minutes, the burst release of $\mathrm{AscH} 2$ from $\mathrm{AscH}_{2}$-MSNs into SGF, SIF, and SBF was $28.6 \%, 62.0 \%$ and $57.1 \%$, respectively. It was indicated that release rate of AscH 2 in SGF was slower than SIF and SBF.

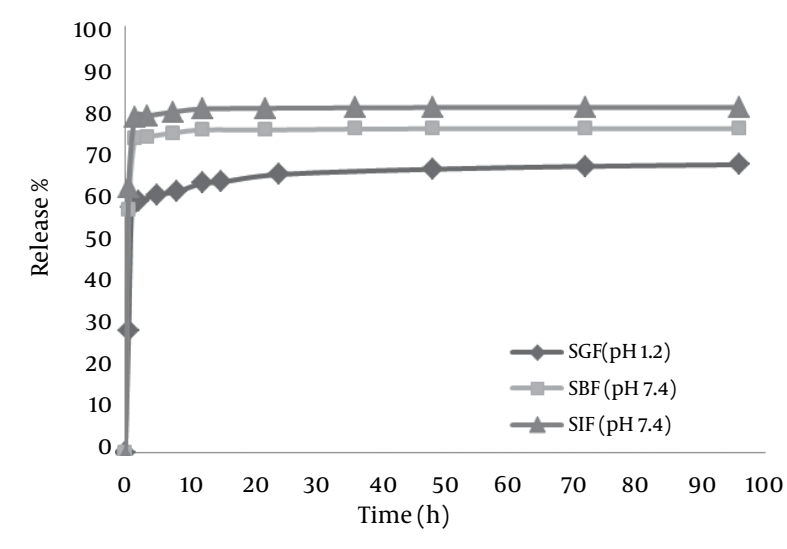

Figure 6. Release Profile of AscH 2 from AscH 2-MSNs into SGF, SIF, SBF.

\section{Discussion}

It was considered that delivery carriers should be designed with respect to several important features such as: biocompatibility of vehicle (mandatory parameter), high loading and protection of the guest molecule, zero premature release before reaching its target, efficient cellular uptake, and effective endosomal escape, controllable rate of release to achieve an effective local concentration, cell and tissue targeting (16).

MSNs have attracted much research attention in the last decades. They are using for their potential applications in the fields of biotechnology and nanomedicine. MSNs are solid materials, which contain a lot of empty pores (mesoporous) arranged in a 2D network of honeycomb-like porous structure. Their unique properties of mesoporous silica nanoparticles include high surface area $\left(>700 \mathrm{~m}^{2}\right.$ . $\left.\mathrm{g}^{-1}\right)$, pore volume $\left(>1 \mathrm{~cm}^{3} \cdot \mathrm{g}^{-1}\right)$, stable mesostructure, tunable pore diameter $(2-10 \mathrm{~nm})$, two functional surfaces (exterior particle and interior pore faces), and modifiable morphology (controllable particle shape and size) (18). In this study, we used MSNs for encapsulation, protection and delivery of vitamin $\mathrm{C}$ in the body. Therefore, MSNs were synthesized and characterized by XRD, TEM, SEM, and N2-adsorption. Resulted XRD patterns showed well-ordered hexagonal mesoporous structure in loaded and unloaded MSNs as shown in Figure 1. In addition, the a o lattice parameter of AscH 2 -MSNs was larger than that of unloaded MSNs due to filled pores by ascorbic acid.
As expected, the (100) reflection of ascorbic acid loaded MSNs was weaker than that of unloaded MSNs (Figure 4).

Results of $\mathrm{N}_{2}$-adsorption showed that the BET surface areas and $\mathrm{BJH}$ adsorption volume of AscH 2-MSNs were lower than unloaded MSNs, representative that the surface modification reaction occurred on the pore surfaces of MSNs.

It was found that the loading efficiency of ascorbic acid may be affected by the position, structure and the number of hydroxyl groups $(\mathrm{OH})$ and carboxyl group on the benzene ring. In addition, the high hydrophilicity property of ascorbic acid makes it less attractive to the hydrophilic nano channels of MSNs.

As shown in Figure 6, it was observed that the burst release of AscH 2 from nanoparticles into SGF was slower than that of in slightly alkaline $\mathrm{pH}$ (7.4) and SBF. It was found that at $\mathrm{pH} 7.0$ the dominant form for vitamin $\mathrm{C}$ is $\mathrm{AscH}^{-}$(99.9\%) with low concentrations of $\mathrm{AscH}_{2}$ and Asc ${ }^{2-}$. It means that $\mathrm{L}$-ascorbic acid is in anion form at $\mathrm{pH} \geq 7$ and the amount of $\mathrm{Asc}^{2-}$ will increase by a factor of ten with a one unit increase in $\mathrm{pH}$ (3). In addition, as the $p K a$ values (AscH 2 has two $p K a$ values due to existence of hydroxyl and carboxyl groups on the ring, $p k 1$ is 4.2 and pK2 is 11.6) of AscH 2 are around 4.2, the anions derived from proton dissociation will dominate in neutral system (occurrence $>99.5 \%$ ) (3). As a result, the sampling of released AscH 2 from nanoparticles into SBF and SIF was performed at every 30 minutes.

It was found that at $\mathrm{pH}<5$, only the carboxyl group of the AscH 2 are negatively charged, it made ionic interaction between carboxyl group of AscH 2 and the hydroxyl groups of MSNs surface. At $\mathrm{pH}>7$, the hydroxyl groups of organic acids started to deprotonate and all the anionic forms of AscH 2 were produced (3). As a pervious mentioned when $\mathrm{pH}$ of the solution increased to 7.4, a strong electrostatic repulsion generated between the surface of MSNs and the AscH 2 molecules to trigger of large amounts of AscH 2 in the SBF.

In conclusion, the synthesized MSNs with $2.44 \mathrm{~nm}$ pore diameter were nominated to load AscH 2 as an antioxidant. Thereafter we investigated its release into SGF, SIF, and SBF. Vitamin $C$ has antioxidant activity and dissolves in water which produces acidic solution; as a result to its action it cannot be stored in the body. It was found that the loading amount of Vitamin $C$ was dependent to the amount of hydroxyl groups on the surface and inner pore of MSNs or steric inhibition of molecule structure. On the other hand, the loading of AscH 2 was heavily dependent on the surface chemical moiety of MSNs due to the presence of an ionic interaction between the carboxyl and hydroxyl groups of ascorbic acid.

In addition, the presence of an ionic interaction between the carboxyl and $\mathrm{OH}$ groups of Vitamin $\mathrm{C}$ influences on the vitamin $C$ release and loading into MSNs. It was found that the release of AscH 2 in acidic solution 
was slower than slightly alkaline solution. The results of the present study indicated that MSNs can be developed and designed for the sustained release of unstable antioxidants.

\section{Acknowledgements}

We acknowledge Iranian National Standardization (INSO) which provided some instrumental facilities.

\section{Authors' Contribution}

All authors have participated equally.

\section{Financial Disclosure}

There is no conflict of interest.

\section{Funding / Support}

The study is self-funded.

\section{References}

1. Naidu KA. Vitamin C in human health and disease is still a mystery? An overview. Nutr J. 2003;2:7.

2. Frei B, Trabe MG. The new US Dietary Reference Intakes for vitamins C and E. Redox Rep. 2001;6(1):5-9.

3. Du J, Cullen JJ, Buettner GR. Ascorbic acid: chemistry, biology and the treatment of cancer. Biochim Biophys Acta. 2012;1826(2):443-57.

4. Hallberg L. Bioavailability of dietary iron in man. Annu Rev Nutr. 1981;1:123-47.

5. Khan MM, Martell AE. Metal ion and metal chelate catalyzed oxidation of ascorbic acid by molecular oxygen. II. Cupric and ferric chelate catalyzed oxidation. JAm Chem Soc. 1967;89(26):7104-11.

6. Chen Q, Espey MG, Krishna MC, Mitchell JB, Corpe CP, Buettner GR, et al. Pharmacologic ascorbic acid concentrations selectively kill cancer cells: action as a pro-drug to deliver hydrogen peroxide to tissues. Proc Natl Acad Sci U S A. 2005;102(38):13604-9.

7. Chen Q, Espey MG, Sun AY, Pooput C, Kirk KL, Krishna MC, et al Pharmacologic doses of ascorbate act as a prooxidant and decrease growth of aggressive tumor xenografts in mice. Proc Natl Acad Sci US A. 2008;105(32):11105-9.

8. Basili S, Tanzilli G, Mangieri E, Raparelli V, Di Santo S, Pignatelli $P$, et al. Intravenous ascorbic acid infusion improves myocardial perfusion grade during elective percutaneous coronary intervention: relationship with oxidative stress markers. JACC Cardiovasc Interv. 2010;3(2):221-9.
9. Taddei S, Virdis A, Ghiadoni L, Magagna A, Salvetti A. Vitamin $C$ improves endothelium-dependent vasodilation by restoring nitric oxide activity in essential hypertension. Circulation. 1998;97(22):2222-9.

10. Valero MP, Fletcher AE, De Stavola BL, Vioque J, Alepuz VC. Vitamin $C$ is associated with reduced risk of cataract in a Mediterranean population. J Nutr. 2002;132(6):1299-306.

11. Rosenholm Jessica, Sahlgren Cecilia, Linden Mika. Cancercell targeting and cell-specific delivery by mesoporous silica nanoparticles. J Mater Chem. 2010;20(14):2707-13.

12. Coti KK, Belowich ME, Liong M, Ambrogio MW, Lau YA, Khatib $\mathrm{HA}$, et al. Mechanised nanoparticles for drug delivery. Nanoscale. 2009;1(1):16-39.

13. Lee Chia-Hung, Cheng Shih-Hsun, Wang Yu-Jing, Chen Yu-Ching, Chen Nai-Tzu, Souris Jeffrey, et al. Near-Infrared Mesoporous Silica Nanoparticles for Optical Imaging: Characterization and In Vivo Biodistribution. Adv Funct Mater. 2009;19(2):215-22.

14. Lin Yu-Shen, Tsai Chih-Pin, Huang Hsing-Yi, Kuo Chieh-Ti, Hung Yann, Huang Dong-Ming, et al. Well-Ordered Mesoporous Silica Nanoparticles as Cell Markers. Chem Mater. 2005;17(18):4570-3.

15. Vivero-Escoto JL, Slowing, II, Wu CW, Lin VS. Photoinduced intracellular controlled release drug delivery in human cells by gold-capped mesoporous silica nanosphere. J Am Chem Soc. 2009;131(10):3462-3.

16. Rosenholm JM, Peuhu E, Bate-Eya LT, Eriksson JE, Sahlgren C, Linden M. Cancer-cell-specific induction of apoptosis using mesoporous silica nanoparticles as drug-delivery vectors. Small. 2010;6(11):1234-41.

17. Zhang Y, Zhi Z, Jiang T, Zhang J, Wang Z, Wang S. Spherical mesoporous silica nanoparticles for loading and release of the poorly water-soluble drug telmisartan.J Control Release. 2010;145(3):25763.

18. Mortera R, Vivero-Escoto J, Slowing, II, Garrone E, Onida B, Lin VS. Cell-induced intracellular controlled release of membrane impermeable cysteine from a mesoporous silica nanoparticle-based drug delivery system. Chem Commun (Camb). 2009(22):3219-21.

19. Lin Q, Huang Q, Li C, Bao C, Liu Z, Li F, et al. Anticancer drug release from a mesoporous silica based nanophotocage regulated by either a one- or two-photon process. J Am Chem Soc. 2010;132(31):10645-7.

20. Bernardos A, Aznar E, Coll C, Martinez-Manez R, Barat JM, Marcos $\mathrm{MD}$, et al. Controlled release of vitamin B2 using mesoporous materials functionalized with amine-bearing gate-like scaffoldings. J Control Release. 2008;131(3):181-9.

21. Wu Z, Jiang Y, Kim T, Lee K. Effects of surface coating on the controlled release of vitamin $\mathrm{B} 1$ from mesoporous silica tablets. $J$ Control Release. 2007;119(2):215-21.

22. Xu W, Gao Q, Xu Y, Wu D, Sun Y, Shen W, et al. Controllable release of ibuprofen from size-adjustable and surface hydrophobic mesoporous silica spheres. Powder Technol. 2009;191(1-2):13-20. 